\title{
El Mar kuna. Representación y uso de los recursos marinos en Kuna Yala (Panamá)
}

\author{
Mònica Martínez Mauri \\ Universitat Autònoma de Barcelona \\ Ecole des Hautes Etudes en Sciences Sociales
}

\section{Introducción}

En las últimas décadas, la etnografía americanista se ha nutrido de extensas monografías sobre las relaciones entre los humanos y los ecosistemas forestales. Con el tiempo, la noción de "indígena" ha pasado a ser sinónima de "habitante de la selva", relegando al olvido numerosas sociedades indígenas de pescadores. En general se ha mostrado poco interés por los ecosistemas marinos de América Latina.

La literatura etnográfica sobre el pueblo kuna constituye un buen ejemplo de este olvido. Aunque las monografías y artículos sobre los kunas se cuentan por centenares, bastan los dedos de una mano para sumar los que estudian el uso de los recursos marinos. En el siglo XX sólo los trabajos de Gary Marshall Hasbrouck (1985); Susan Charnley y Cebaldo de León (1986); Verena Sandner (1998); y Jorge Ventocilla, Heraclio Herrera y Valerio Núñez (1995) contemplan esta problemática. Los tres primeros abordaron la relación con el mar de forma parcial, centrándose en el estudio de la pesca sin prestar mucha atención a las representaciones simbólicas del mar. El libro de Ventocilla, Herrera y Núñez -el único que ha sido publicado- sólo consagró un capítulo a los problemas medioambientales que sufren los ecosistemas marinos.

Actualmente, la población de Kuna Yala vive en 14 comunidades costeras y 60 islotes $^{1}$ cercanos a la costa, sin agua dulce y densamente poblados. Regularmente hombres y mujeres se desplazan al continente para obtener productos agrícolas, leña,

\footnotetext{
${ }^{1}$ No todos los islotes tienen la categoria de comunidad. Algunos, por ser de talla muy reducida, dependen de otras comunidades.
} 
agua; visitar el cementerio; y lavar ropa en el río. El mar es la realidad que les rodea después de abastecerse de los frutos de la "Madre Tierra". En él pescan, se sumergen en busca de langostas, admiran las crecidas del río, contemplan los delfines saltar, y perciben sirenas y diablos. En la mesa, el pescado acompaña los productos del campo. Aporta el $80 \%$ de las proteínas animales a la dieta kuna (Ventocilla et al. 1995). Entonces, si los recursos marinos son tan importantes en la vida cotidiana de los kunas, ¿porque los antropólogos no han investigado la relación material y simbólica que mantiene este pueblo con el mar?

Es imposible encontrar una sola respuesta a esta pregunta. No obstante, hay dos elementos que nos pueden dar una idea del porqué los antropólogos han omitido este tema. Por un lado, los mismos kunas son los primeros en hacer disminuir el interés del investigador por el mar. Durante los primeros días en las islas, no le dejaran de repetir que sus antepasados migraron del continente a las islas bajo la presión de los españoles, que la madre tierra es vital para su supervivencia y que el pueblo kuna siempre ha luchado por su tierra. Por si fuera poco, cada vez que el antropólogo proponga ir a bañarse a una de las hermosas playas de las muchas islas deshabitadas, todos lo miraran indiferentes, sin experimentar ninguna necesidad de sumergirse en el agua caliente, salada y poblada de peligros del Caribe. Si al cabo de unas semanas al paciente investigador todavía le queda alguna duda de lo equivocado que estaba al decidirse por estudiar el mar kuna, sólo le falta tropezar con unas últimas dificultades para abandonar el tema: la increíble variedad de recursos marinos y la necesidad de contar con un marinero experto con quien salir a pescar ${ }^{2}$.

Dejando de lado las dificultades iniciales, este estudio sobre la apropiación material y simbólica del mar muestra, una vez más, hasta qué punto nuestra visión de la naturaleza y, por supuesto, de la costa y el mar, no es universalmente compartida por el resto de la humanidad. Aunque la mundialización acentúe la expansión del modelo occidental de relación con la naturaleza, en Kuna Yala todavía perviven cantos, tabúes,

\footnotetext{
${ }^{2}$ Para hacerse a la idea de lo que representa esta biodiversidad, se puede tener en cuenta este dato: en un año de trabajo de campo en una comunidad isleña, recopilé 172 nombres de criaturas marinas (peces, crustáceos, corales y mamíferos marinos). Empezar por conocer las taxonomías locales relativas a los recursos marinos implica una gran inversión de tiempo.
} 
miedos y creencias que constituyen un modelo de representación diferencial. Como ha puesto de manifiesto la antropología ecológica y la antropología simbólica, la naturaleza no es natural, es una construcción social.

Además de documentar aspectos poco conocidos por la etnografía kuna, esta reflexión pretende aportar un granito de arena al complejo debate sobre la construcción social de la "cultura-naturaleza"33 (Latour 1991; Descola 1996) y las consecuencias del Grand Partage 4 . Coincidiendo con el punto de vista de Descola y de Latour, en la segunda parte de este artículo se analizan las relaciones con el medio ambiente a partir de:

1. Los procesos de objetivación de los no humanos, es decir, las propiedades atribuidas a los espíritus asociados a los recursos marinos, como por ejemplo, la capacidad de apropiarse del purba (alma) de los humanos o de dificultar el parto.

2. Las categorías de mediación: la presencia de seres híbridos con acceso a los diferentes niveles del universo, como por ejemplo la sirena.

\section{La apropiación material del mar en Kuna Yala}

La comarca de Kuna Yala abarca $200 \mathrm{~km}$. de la costa atlántica panameña, entre cabo Tiburón (frontera con Colombia) y un punto situado a $120 \mathrm{~km}$. de Puerto Colón.

${ }^{3}$ Cf. Bruno Latour (1991). En este célebre ensayo de antropología simétrica, Latour muestra cómo la modernidad, separando el orden natural del social, ha construido la naturaleza como una esfera autónoma. Los modernos al construir a los otros, y al excluir a los no humanos de la cultura, provocaron el Grand Partage. Entonces, al poner la naturaleza entre paréntesis, la noción de cultura se convirtió en un artefacto que en realidad no existe. Según Latour, las culturas no se pueden comparar porque son una ilusión. La antropología debe centrarse en la comparación de las naturalezas-culturas. $C f$. Philippe Descola (1996). El objetivo de la antropología debe ser la comparación y la descripción de sistemas locales de relación con el medio ambiente. Estos sistemas son combinaciones estructuradas por compatibilidades entre un nombre finito de elementos, básicamente dos: 1. relaciones de objetivación de los humanos y de los no humanos, y 2. modos de categorización de los sistemas de mediación.

${ }^{4}$ Muchos autores utilizan la expresión Grand Partage ("the Great Divide") para resumir la división que ellos creían observar entre el espíritu científico y el espíritu pre-científico. Esta división corresponde con la existente entre sociedades occidentales modernas y las "otras" sociedades. (Cf. Latour 1988: 27-64) 
Comprende más de 300 islas de origen coralino y según el último censo nacional, la población asciende a 32.446 habitantes $^{5}$.

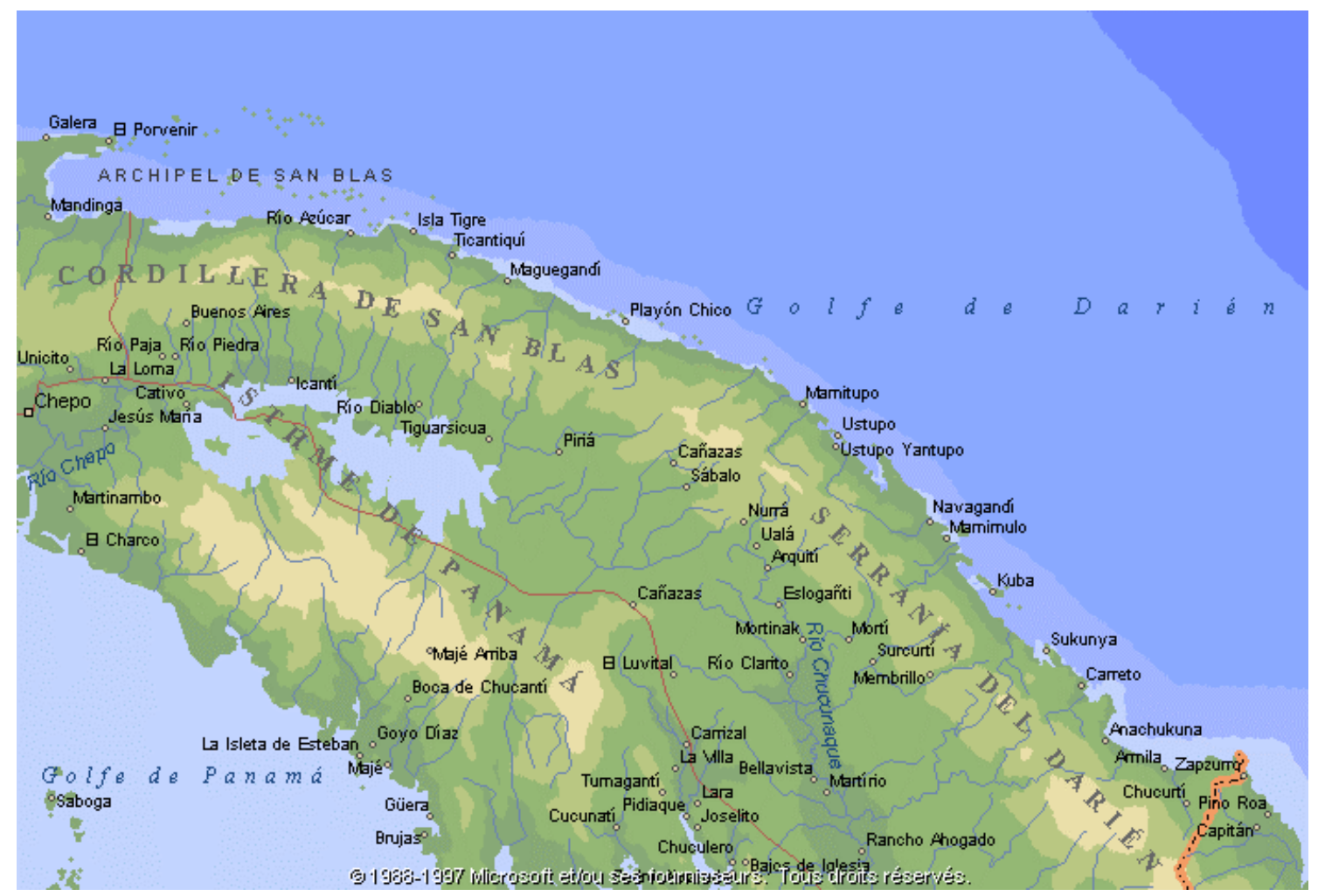

Mapa de la costa y cordillera de San Blas (Co marca de Kuna Yala)

Las comunidades de la comarca no están comunicadas por tierra con el resto del territorio nacional. Desde hace siglos el mar es la principal vía de comunicación con el exterior. Los contactos comerciales y políticos con grupos foráneos forman parte de la historia del pueblo kuna. Del siglo XVI hasta el XVIII se aliaron y comerciaron con los piratas ingleses y franceses. Entre 1690-1757 establecieron relaciones con la colonia de hugonotes franceses, y entre 1698-1700 con la escocesa. A principios del siglo XIX, cuando empezó la migración gradual hacia las islas, desarrollaron el comercio del coco con los colombianos. Desde la segunda mitad del siglo XX, cada año miles de turistas llegan a la región a bordo de lujosos cruceros. Es evidente que los kunas, además de vivir muy cerca de una de las principales vías del comercio internacional (el canal de Panamá), no están cerrados al mundo.

\footnotetext{
${ }^{5}$ Contraloría General de la República de Panama, 2000.
} 
Como he anunciado en la introducción, los kunas subsisten explotando los recursos de varios ecosistemas marinos y terrestres. Cada día por la madrugada, salen de sus casas y reman hasta la tierra firme en busca de agua, leña y productos agrícolas. Los hombres practican una agricultura de subsistencia basada en el sistema de roza y quema. Cultivan cocos, plátanos, guineos, yuca, caña de azúcar, maíz, arroz, ñame, otoe, cacao, piñas y otros productos de menor importancia. Trabajan individual y colectivamente en las parcelas de la familia, del pueblo o de una sociedad (grupo organizado de comuneros). Cuando consiguen municiones en Panamá o Colón, salen a cazar al monte. La caza, aunque es inapreciable en la dieta de los kunas, tiene una gran importancia simbólica. Las presas no se comercializan, se redistribuyen entre los familiares y amigos del cazador.

Otra de las tareas que ocupa las horas de los kunas es la pesca. Como en otros ámbitos de la vida cotidiana y ritual, en la práctica de esta actividad domina una estricta división sexual del trabajo. Los hombres aportan el pescado a la unidad doméstica y sus esposas, madres o suegras se encargan de limpiarlo, cocinarlo y conservarlo. Las mujeres muy raramente salen a pescar solas. A veces van a tirar la red junto con sus maridos o participan en las giras de pesca de varios días para ahumar el pescado. 


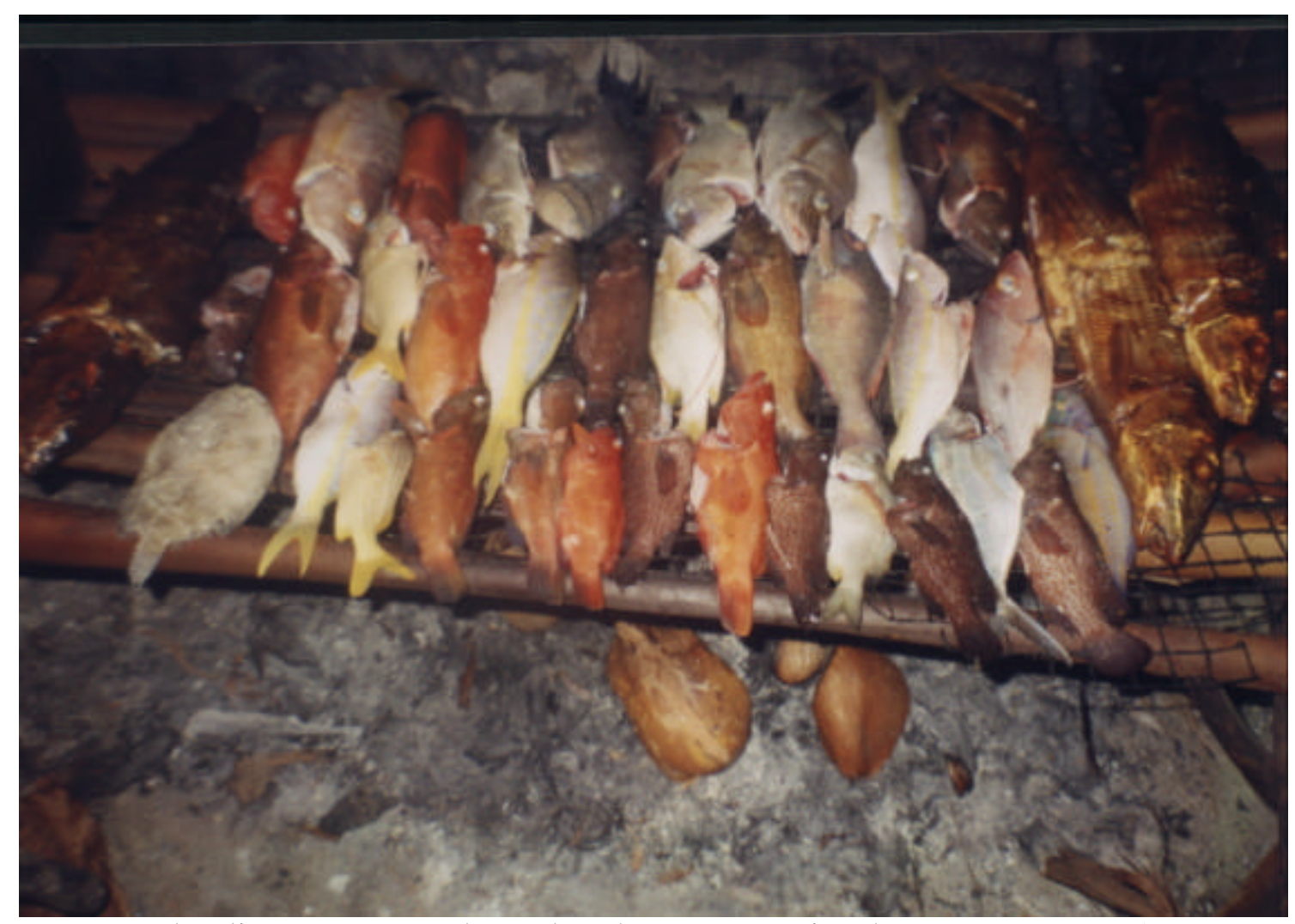

Pescados listos para ser ahumados durante una gira de pesca. Foto: MARTINEZ MAURI, 2003.

En Kuna Yala la pesca todavía es una actividad artesanal. Aunque algunos hombres tienen redes y venden pescado cuando tienen suerte, la mayoría sólo sale al mar para alimentar a su familia ${ }^{6}$. Practican la pesca con anzuelo y carnada (viva o muerta); carrizo; chuzo o arpón; red de trasmallo; red de cuerda y nasa (trampa). Cada una de estas técnicas es aplicada en función del pez que se quiere capturar, del estado del mar (viento, marea y corrientes marinas), de los medios técnicos disponibles y de las necesidades rituales. Por ejemplo, si un hombre necesita grandes cantidades de pescado para celebrar la fiesta de pubertad (inna mutiki o inna dummat ${ }^{7}$ ) de una de sus hijas, es muy probable que busque a alguien con red para ir a pescar a un lugar poco frecuentado.

La explotación de los lugares de pesca también depende de los medios técnicos y de las condiciones meteorológicas. Los kunas definen los sitios de pesca en base a tres

\footnotetext{
${ }^{6}$ Hay un sector de hombres, los langosteros, que se dedican a la pesca y comercialización de la langosta, el pulpo, el centollo, los langostinos y la gambobia. Son buceadores expertos (se sumergen a pulmón libre) que arriesgan diariamente sus vidas a cambio de poco dinero. $C f$. Abelló y Díaz $(2001,2003)$, Spadafora, (2000) y Ventocilla et al. (1995).

${ }^{7}$ Cf. Prestán (1975)
} 
factores: 1. el fondo marino, 2. la localización, y, 3. la profundidad. Según el fondo marino distinguen entre tres tipos de sitios: kagan (algas), aqqua (corales) y ukup (arena). A partir de los puntos de referencia consideran que van a pescar: magatba (al mar abierto), tubgan (a las islas cercanas no habitadas) o diuar kaka (a la desembocadura del río). Finalmente, cuando tienen en cuenta la profundidad, las aguas son: dinnagua ("seco", aguas poco profundas) o dinna suly ("no seco", aguas muy profundas).

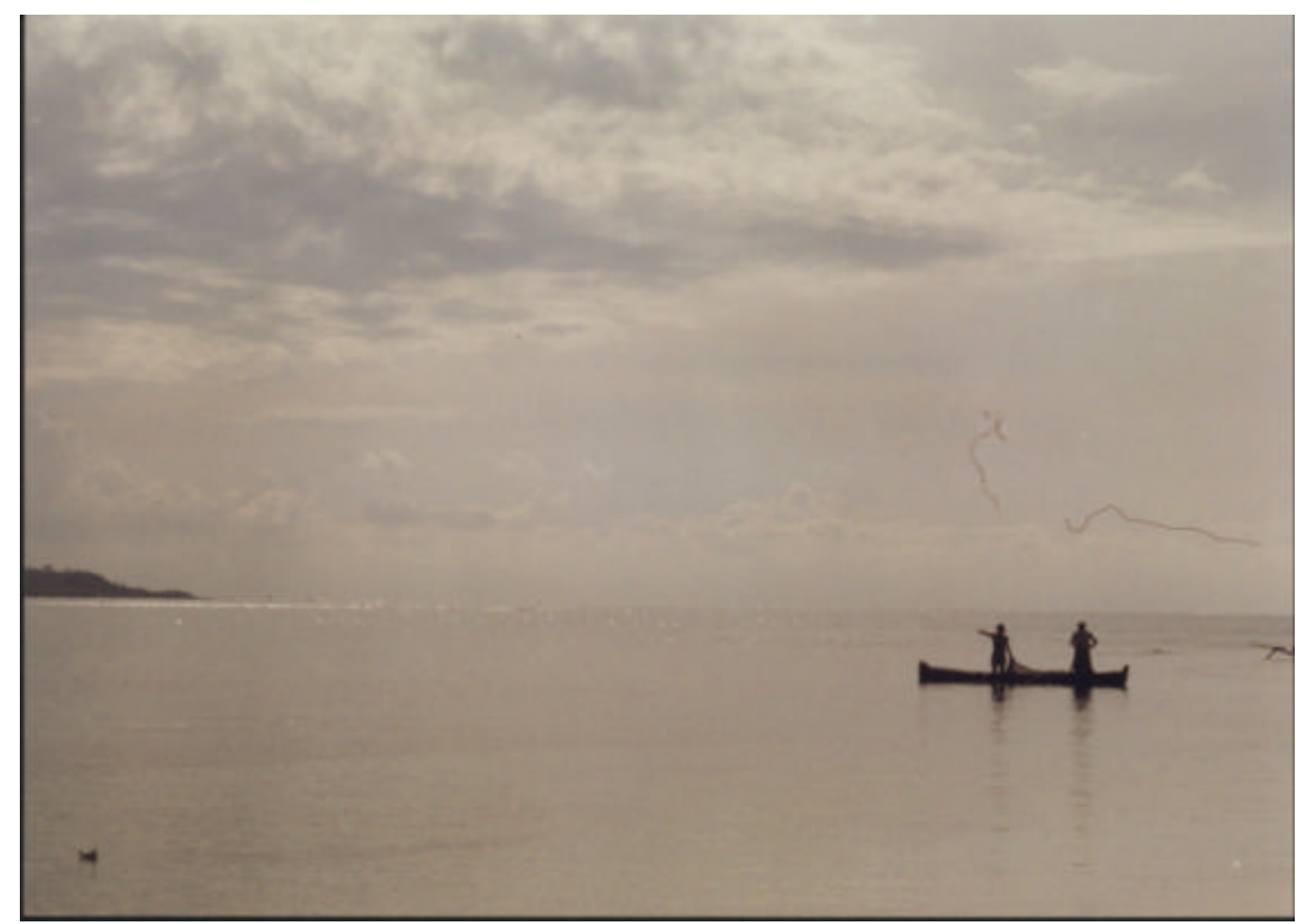

Pescadores buscando un buen lugar para coger sardinas. Foto: MARTINEZ MAURI, 2003.

Normalmente el acceso al mar es libre. Cada persona conoce lugares secretos donde abunda una determinada especie de peces. Estos sitios se llaman ya ("agujero") y generalmente se transmiten de padres a hijos o de tíos a sobrinos. Hoy en día, además de explotar los ya de los antepasados, la proliferación de cayucos con motor fuera borda permite extender el radio de acción del pescador.

Algunos lugares no son accesibles a todos los kunas. Para pescar en las aguas del grupo de islas que forman los cayos Maokí, en el extremo Noreste de la comarca, hay 
que obtener un permiso de las autoridades locales. Las islas de Maokí son plantaciones de cocos y están bajo el control de varias familias de los seis pueblos (conjunto de comunidades del sector central de Kuna Yala). Si bien entre los kunas no existe la propiedad privada de la tierra o el mar, se respetan derechos de posesión. Por esta razón los que no son de estas comunidades deben pedir permiso y pagar una especie de peaje para pescar en Maokí. Las autoridades de los seis pueblos suelen controlar a los pescadores que acuden a esta zona.

En las últimas décadas muchos lugares de pesca explotados generación tras generación han dejado de ser productivos. Los ancianos recuerdan tiempos en los que no hacía falta ir tan lejos para encontrar langostas o bancos de peces. Alrededor de las islas había todo lo que necesitaban. La disminución de algunas especies se debe al declive de la población de corales, un fenómeno bien documentado por los biólogos (Lasker et al. 1984, Shulman \& Robertson 1996, Sandner 1998, Abelló y Díaz 2001 y 2003, Guzmán et al. 2003). Guzmán ha calculado que los fondos marinos de Kuna Yala han pasado de una cobertura coralina del 60\% en 1970, al 13\% en el año 2000 (Guzmán et al. Op. cit. : 1398). Si bien todavía no se ha valorado el impacto que han podido tener las practicas kunas sobre el medio marino (Guzmán et al. Op.cit. : 1397) todo parece indicar que la contaminación de las aguas es la principal causa de degradación de los arrecifes coralinos.

Es difícil valorar la responsabilidad de los kunas en la degradación del medio. El calentamiento global de la tierra y las crecidas de los ríos de la región también contribuyen a la extinción de los corales. Sin embargo, se pueden identificar algunas prácticas contaminantes. Una de ellas es la costumbre de tirar los residuos domésticos al $\operatorname{mar}^{8}$. Aunque hay desechos orgánicos, los kunas también consumen pilas, detergentes, latas y otros productos no biodegradables. Principalmente, las substancias que vierten al mar contienen: microorganismos, materia orgánica, sales minerales biogenas y contaminantes químicos inorgánicos. Los kunas también provocan desequilibrios artificiales en el medio. Modifican el ecosistema marino apropiándose de corales

\footnotetext{
${ }^{8}$ Cf. Forichon (2003)
} 
muertos para la construcción de muelles y para agrandar las islas rellenado las orillas ${ }^{9}$. Todos estos factores provocan la migración de algunas especies marinas (Bellan y Pérès op. cit. : 93-94).

\section{Las representaciones kunas del mar}

Después de observar cómo los kunas pescan y modifican bs ecosistemas marinos, ha llegado el momento de ver cómo perciben el mar. Para ello analizaré el lenguaje, los tabúes, el arte, la enfermedad y los mitos en relación a los recursos marinos.

Ahora bien, antes de empezar con el análisis de estos elementos, ¿no sería pertinente reflexionar sobre nuestra propia percepción del mar? Pese a que pueda resultar un tanto extraño, nuestra visión del mar, la playa y la costa no deja de ser una construcción social. No es ni mejor ni peor, ni más cierta ni más falsa que la elaborada por el pueblo kuna. En nuestro entorno social, cuando pensamos en el mar, enseguida nos vine a la mente la idea de desasosiego. Con el transcurso de los siglos, nuestra sociedad ha elaborado una imagen agradable del mar y la playa. Ambos lugares evocan situaciones de placer y bienestar. Hemos dotado al mar de propiedades curativas tanto a nivel físico como mental. Pero esta visión no es universal. Se fundamenta en el Grand Partage, o en otras palabras, en la disociación entre naturaleza y sociedad.

El trabajo de Alain Corbin sobre el deseo por la playa y la costa en Occidente, muestra como se ha construido esta representación actual. El autor sitúa el nacimiento de la visión moderna del océano, el mar, la playa y la costa entre el 1750 y 1840. Antes, la sociedad europea percibía el mar como un gran abismo, lleno de misterios y sin puntos de referencia (Corbin op. cit. 11-13). En la literatura grecorromana aparece como un lugar enigmático por excelencia. Los clásicos veían la costa como el sitio donde llegaban los excrementos del mar. A mediados del siglo XVII con los avances de la oceanografía, la teología natural y las obras de los poetas barrocos, Occidente empieza a admirar positivamente el vaivén de las olas. En este momento se produce la ruptura entre los sistemas populares y las concepciones sabias de apreciación de la naturaleza.

\footnotetext{
${ }^{9}$ Para una categorización de los agentes contaminantes en el medio marino $C f$. Bellan y Pérès, 1994 [1974] :8-16.
} 
Esto da lugar a una nueva correlación entre el mundo físico y el espiritual, entre lo humano y lo divino, entre el hombre y el universo (Corbin op. cit. :24-35).

Al comparar la representación occidental del mar con la kuna aparecen grandes diferencias. Para empezar, es conveniente comentar las palabras kunas que designan lo que nosotros llamamos "pescar". En tulekaya (lengua kuna) la acción de atrapar los peces depende de la técnica empleada. Si arponeamos el pescado la acción se denomina ua makke ("cazar el pez"), si lo capturamos en red se dice saki mie ("tirar la red") o ua kae ("agarrar el pez"), y si conseguimos que pique el anzuelo, ua soe. En esta enumeración, destaca la utilización de makke para referirse a la captura de peces y de animales terrestres. Este hecho vendría a confirmar la hipótesis de Leap (1977) según la cual las diferencias entre "pescar" y "cazar" son inexistentes en muchas sociedades.

En general, la definición de "pesca" o "recolección de recursos marinos" es ambigua (Palsson 1991: 37). No obstante, las diferencias observadas en el léxico kuna muestran un deseo por definir y concretizar la acción. Para los kunas "pescar" no consiste solame nte en atrapar peces bajo el agua. Lo importante es saber cómo han sido capturados.

Para ir más allá y no sólo analizar la pesca bajo el prisma de las técnicas utilizadas, es necesario considerar el marco social en el cual se desarrolla (Palsson 1991: 38). Acheson (1981) cree que las sociedades pescadoras introducen instituciones para reducir la competencia y extender los riesgos de producción. Es muy interesante aplicar esta teoría al caso de los kunas. Como he mostrado más arriba, el pueblo kuna se instala en las islas y la costa a partir de la primera mitad del siglo XIX. La migración gradual hacia el mar provocó grandes cambios: las mujeres abandonaron los trabajos agrícolas y la pesca substituyó a la caza como principal fuente de proteína animal. A partir de la segunda década del siglo XX se crean las Sociedades y se instaura el trabajo cooperativo en la agricultura, el comercio y la pesca. Si bien muchos antropólogos han constatado el auge del cooperativismo en ese momento (Puig 1946:56; Stout 1947; Holloman 1969:198-224; Shatto, 1969; Howe, 1974 y 1986; Stier 1979: 101; Tice 1995 :127), es arriesgado relacionarlo con la explotación generalizada de los recursos marinos. Es imposible saber hasta qué punto la pesca es la responsable. Otros factores 
pueden estar detrás de estas nuevas formas de organización social del trabajo. Entre ellos, la monetarización parcial de la economía local, la migración a la ciudad o la degradación del medio ambiente. No hay que exagerar el papel de la pesca, ya que quizás nos dejaríamos llevar por los estereotipos que pesan sobre las sociedades pescadoras $^{10}$.

Para los kunas, un hombre sabio es aquél que se dedica a la agricultura y a la pesca. Ambas actividades son complementarias. Una persona que sólo salga a pescar, no será recordada por los suyos. Cuando se muera, sus hijos e hijas no recibirán ninguna parcela de tierra en herencia. Si hay que elegir, siempre es mejor casarse con un agricultor que deteste la pesca, que con un marinero.

En la tradición kuna, la tierra firme, con sus ríos y montañas, es la "madre tierra". Existen varias versiones del relato sobre la creación del mundo. Uno de ellos narra como Pab Dummat (el gran padre) y Nan Dummat (la gran madre) encendieron el Sol, la luna, las estrellas y crearon todo lo que hoy rodea a los kunas. El gran padre formó la madre tierra y la modeló con la ayuda de Nan Dummat (Cf. Wagua (comp.) 2000:1113). Otra versión recopilada por Mac Chapin sostiene que la tierra es el propio cuerpo de Nan Dummat. De su unión sexual con Pab dummat, nacieron todas las plantas, animales y humanos. En un momento inicial, las criaturas que la Gran Madre traía al mundo eran espirituales, no tenían substancia física. Los creadores estaban preparando el mundo para los kunas. Cuando ya casi todo estaba listo para la llegada del pueblo elegido, la madre y el padre engendraron un espíritu femenino llamado Muu ${ }^{11}$. Entonces, Pab Dummat y Nan Dummat abandonaron la labor reproductora, colocaron a Muu en el cuarto nivel del universo y le pidieron que se hiciera cargo de la reproducción de los animales y los hombres. Los creadores también instalaron a Olopenkikkiler y su

\footnotetext{
${ }^{10}$ Desde el siglo XVIII, los relatos sobre los pueblos de la costa exaltan la imagen del "bon peuple" igualitario, que escapa a la movilidad social y tiene una calidad de vida excepcional gracias a una alimentación a base de pescado. Los románticos exageraron las gestas heroicas de los marineros. Los presentaron como una especie en vías de extinción y enamorada del mar (Corbin, op.cit.: 239-253). Algunas de estas imágenes han sobrevivido al siglo XVIII y forman parte de nuestros estereotipos sobre los pueblos de pescadores.

${ }^{11}$ En tulekaya Muи significa: "comadrona", "abuela", "mar".
} 
mujer Olokkekkepyai, los encargados de mandar las plantas a la superficie de la tierra, cerca de Muu (Chapin 1983 :62-67).

Los hombres versados en la tradición oral kuna todavía recuerdan un canto mitológico (igar) que describe el nacimiento y el camino que recorren los recursos marinos hasta llegar a Kuna Yala. Debajo del mar, en el cuarto nivel del universo, donde vive Muu, existe un mundo paralelo. En este lugar hay islas habitadas por sirenas, tiburones, pulpos, pargos, rayas etc. gobernados por sus respectivos jefes. También hay un río salado (Osiskun diuar o Palu diuar) donde abunda todo tipo de animales marinos. Cuando hay escasez de peces en las aguas de Kuna Yala, los que viven en Osiskun Diuar llegan a la superficie del mar a través de unos tubos (cammu). Luego los vientos y las corrientes marinas les ayudan a repoblar los mares.

Los tubos (сатmu) corresponden a los remolinos (piria) que aparecen en algunos puntos del mar. En la primera etnografía moderna sobre Kuna Yala, el barón Erland Nordenskiöld (1928) sostiene que para los kunas los remolinos (piria) son lugares sagrados. En ellos viven los ponigana, seres con cola de pez, o con dos cabezas y ojos debajo de los brazos. Son peligrosos, ya que se apoderan de la fuerza (niga) o del alma (purba) de los humanos (Nordenskiold, 1928). Según Mac Chapin, para los kunas los remolinos que se forman en los ríos durante la estación lluviosa y las turbulencias del mar de los meses de viento, representan la sangre menstrual de la madre tierra que anuncia el nacimiento de los peces (Chapin 1983: 432). Los kunas enfatizarían la naturaleza maternal de la tierra llamando al océano Muи (abuela) y a los ríos Nana (madre) (Chapin, op. cit. :431).

Las ideas entorno a la gestación y al nacimiento son importantes para comprender la relación simbólica con el mar. Para empezar, es necesario destacar que mientras que en el lenguaje espiritual ${ }^{12}$ la palabra apalisa (de apa: "cuerpo", y lisa: "líquido") significa agua, en el lenguaje coloquial aplis significa sangre. Para los kunas todas las criaturas nacen por medio del agua, ya que esta representa la sangre menstrual de la tierra. (Chapin op. cit. :432). Quizás por esto, cuando los adultos anuncian la llegada de un nuevo miembro de la familia a un niño o niña, le dicen que el delfín le va a traer un

\footnotetext{
${ }^{12}$ La lengua kuna consta de varios registros de orden coloquial, espiritual y ritual. (Cf. Sherzer, 1983)
} 
hermano o una hermana. En Kuna Yala los bebes no los trae la cigüeña, los trae el delfín.

La gestación es un periodo especialmente delicado para una familia kuna. Para evitar la acción de los malos espíritus, se pone en funcionamiento un complejo sistema de protección basado en el respeto de una serie de prohibiciones. Es en este momento cuando entran en juego las representaciones tanto positivas como negativas del mar.

El feto se desarrolla espiritualmente en el cuarto nivel del universo, en la casa de Muu. Si la embarazada o su marido no respetan los tabúes, su bebé puede tener problemas para desarrollarse y salir de la casa de Muu. Por ejemplo, si uno de los progenitores hace daño a una concha, se pueden cerrar las puertas de la casa de Muu impidiendo la salida del bebé al mundo real (Chapin, 1983: 405). Si durante el embarazo no se han respetado los tabúes y aparecen complicaciones durante el parto, se debe acudir a un especialista para que cante el "muu igar" (el camino de muu) ${ }^{13}$.

En el pasado, los espíritus de los animales marinos también jugaban un papel importante durante el parto. Según Nordenskiöld los malos espíritus asociados a la estrella de mar, la serpiente de mar, la tortuga marina y el cangrejo ${ }^{14}$ intentaban complicar el parto. (Nordenskiöld, 1929).

Pese a que con el tiempo la lista de prohibiciones que debe cumplir una mujer embarazada y su marido se va reduciendo, en el sector occidental de la comarca, donde se realizó el trabajo de campo, sigue siendo muy extensa. Entre otros se deben respetar los siguientes tabúes:

- No matar o comer tortuga marina. Si uno de los progenitores no cumple esta prohibición, durante el parto la mujer sangrará como una tortuga marina al ser descuartizada.

- No tocar, matar o comer pulpo. Este animal puede extender sus tentáculos entorno al feto dentro del vientre de la madre. El bebé puede nacer doppe doppe (deforme).

${ }^{13} C f$. Mac Chapin (1983, 407-425); Lévi-Strauss (1974 :213-234).
${ }^{14}$ El cangrejo aparece cuando el bebé sale con los pies por delante. 
- No tocar, matar o comer conchas: los malos espíritus de las conchas pueden cerrar la salida al feto.

- No comer pescados grandes para evitar que la mujer sangre mucho durante el parto (el pescado grande tiene mucha sangre)

- No matar ni hacer daño a animales y seres peligrosos: cocodrilo, tiburón, ansu (sirena de mar), saiba (sirena de río) y serpientes.

A esta lista Mac Chapin añade el Orwaip (Balistes sp.) ya que el espíritu de este pez puede instalarse en el purba del feto y clavarle su espina dorsal (Chapin 1983:396). Sin embargo, durante mi trabajo de campo en Cartí Sugdup nadie me habló de este hecho.

Además de estas prohibiciones, también hay que seguir las recomendaciones de las ancianas. A las mujeres se les recomienda comer yarbi (morena, Gymnothorax funebris) para que el parto sea más rápido y иa matargua (lenguado, Bothus sp.) para que la barriga no crezca demasiado.

Durante los primeros años del desarrollo de la persona no es recomendable comer algunas especies marinas. Los kunas creen que si un niño come tulup nan (cigarro español, Scyllarides aequinoctialis) o sug nan (cangrejo moro, Carpilius corallinus) muy a menudo, se volverá tímido y vergonzoso.

Estos preceptos se fundamentan en la teoría del "somos lo que comemos". Si cómo en el caso de los kunas, somos cuerpo y espíritu, resulta evidente que los productos que ingerimos no sólo transformarán nuestro cuerpo físico, sino que también afectarán nuestro espíritu (purba). Las prohibiciones obedecen a esta lógica. Por ejemplo las mujeres ingieren yarbi (morena) para tener un parto rápido porque la morena tiene un cuerpo viscoso, pero los hombres no pueden comerla porque es tan resbaladiza que les haría difícil trepar a los cocales. Los niños no pueden comer demasiado tulup nan (cigarro español) porque esta criatura tiene fama de ser muy tímida y vergonzosa.

A parte de las prohibiciones que deben respetar las mujeres embarazadas y los niños, también hay tabúes que afectan a toda la población y a los no humanos. Los kunas no pescan ni comen tiburón porque es demasiado feroz y puede transmitir su agresividad a quién lo coma. Los perros, gatos y otros animales domésticos tampoco 
pueden comer ni especies prohibidas ni pescado crudo, si lo hicieran atacarían a sus dueños.

Muchos animales acuáticos se apropian del alma (purba) de los kunas provocándoles enfermedades. Entre estos sobresalen: yarbi (morena), nali (tiburón), taim (cocodrilo), iskin (caiman), nonor (lagarto), kikkir (pulpo) y nidirbi (raya). También hay otros seres malévolos que viven en el mar y pueden provocar la muerte o la locura. Se trata de la ansu (sirena) y el nia (demonio).

Al igual que en la mitología griega se hacía la diferencia entre dos familias de ninfas marinas, las oceánidas y las nereidas ${ }^{15}$, los kunas distinguen entre dos tipos de sirenas: ansu y saiba. La que más miedo infunde a los kunas es la ansu. Nadie la ha visto, pero hasta el niño que apenas habla es capaz de proporcionar una descripción bastante detallada de esta criatura. Mitad pez y mitad humana, vive en el mar, come pescado, duerme de día y molesta de noche. Enloquece a la gente con su belleza y su canto. Como decía un anciano kuna "son tan bellas como las concursantes de Miss universo!" ${ }^{16}$. La saiba viene a ser una versión más pequeña y gentil de ansu. No se apropia del purba de los kunas. Vive en el curso alto del río, en lugares profundos, donde abundan las rocas. Los ancianos hablan de ella, pero ninguno la ha visto o ha oído que hiciera daño a nadie. Simplemente existe porque los antepasados la vieron.

La presencia de sirenas nos remite a una imagen clásica del mar. Hace tiempo, Jean Delumeau constató que en muchas sociedades se produce la asociación entre el mar y la locura (Delumeau 1978 : 37). Las sirenas son el referente común de una infinidad de mitos. En la Odisea de Homero su canto conducía a los marineros al naufragio. Según los mitos griegos, vivían entre las criaturas híbridas, como los centauros y las esfinges, mitad animales y mitad humanos. Algunos aseguraban que eran demonios de la muerte, almas enviadas para captar otras almas (Cordingly 2003: 255). En el arte y literatura de la Europa occidental las sirenas aparecían como mujeres hermosas, de larga cabellera, tentadoras y vanidosas.

15 En las leyendas griegas aparecen las oceánidas, que vivían en los océanos, y hs nereidas, las cincuenta hijas del Dios del mar Nereo y de Doris, que vivían en el Mediterráneo. Según Apolodoro de Atenas había nada mas y nada menos que tres mil oceánidas (Cordingly 2003: 254).

${ }^{16}$ Durante el trabajo de campo se celebró el concurso de Miss Universo en la Ciudad de Panamá. 
A grandes rasgos, la visión kuna de las sirenas coincide con la de la sociedad premoderna. Seguramente, si no fuera por los principios de la ciencia moderna y el "gran partage", las sirenas seguirían formando parte de nuestro universo. La hipótesis que acabó con la existencia de las sirenas sostiene que los marineros las confundían con el dugón o manatí (Cordingly 2003: 258). Otra explicación un poco más elaborada, relaciona el avistamiento de sirenas con el deseo de los capitanes de marina por equiparar sus viajes a las gestas heroicas de la época clásica. (Cordingly 2003: 261).

Las sirenas, así como otros seres marinos, siguen siendo un motivo recurrente en el arte kuna. Las molas, composiciones artísticas a base de telas superpuestas que las mujeres utilizan para decorar sus blusas, representan a los peces desde antaño. Actualmente es casi imposible catalogar a las molas por temas. En un intento desesperado por plasmar todo lo que les rodea, las mujeres reproducen desde la imagen de Mickey Mousse hasta el rastro de un caracol. Sin embargo, en los diseños antiguos ${ }^{17}$ (sergan mola) se pueden apreciar figuras geométricas, hojas, flores, caminos, animales terrestres y criaturas marinas.

\footnotetext{
${ }^{17}$ Cf. Perrin, (1998).
} 


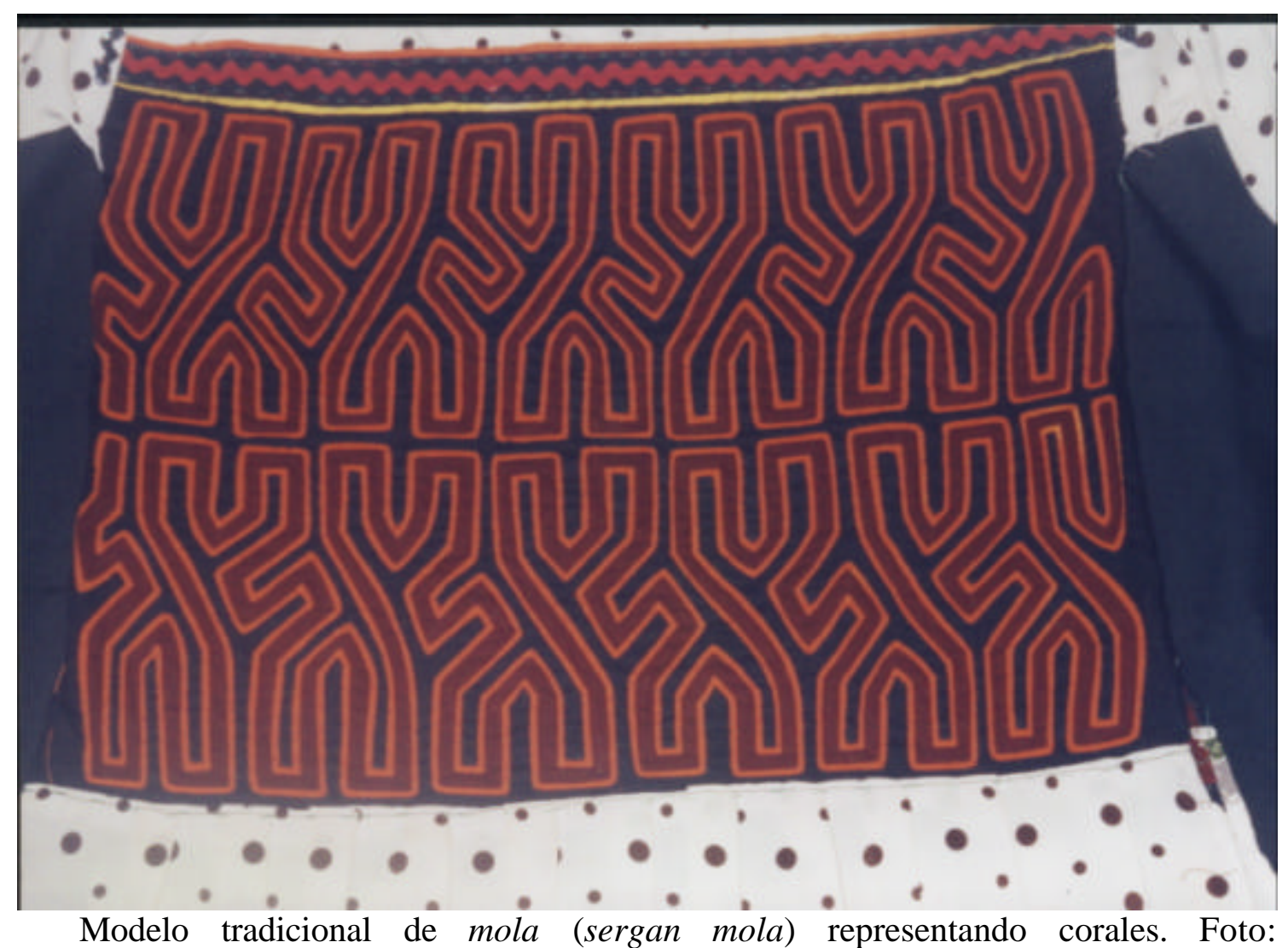

MARTINEZ MAURI, 2003. 


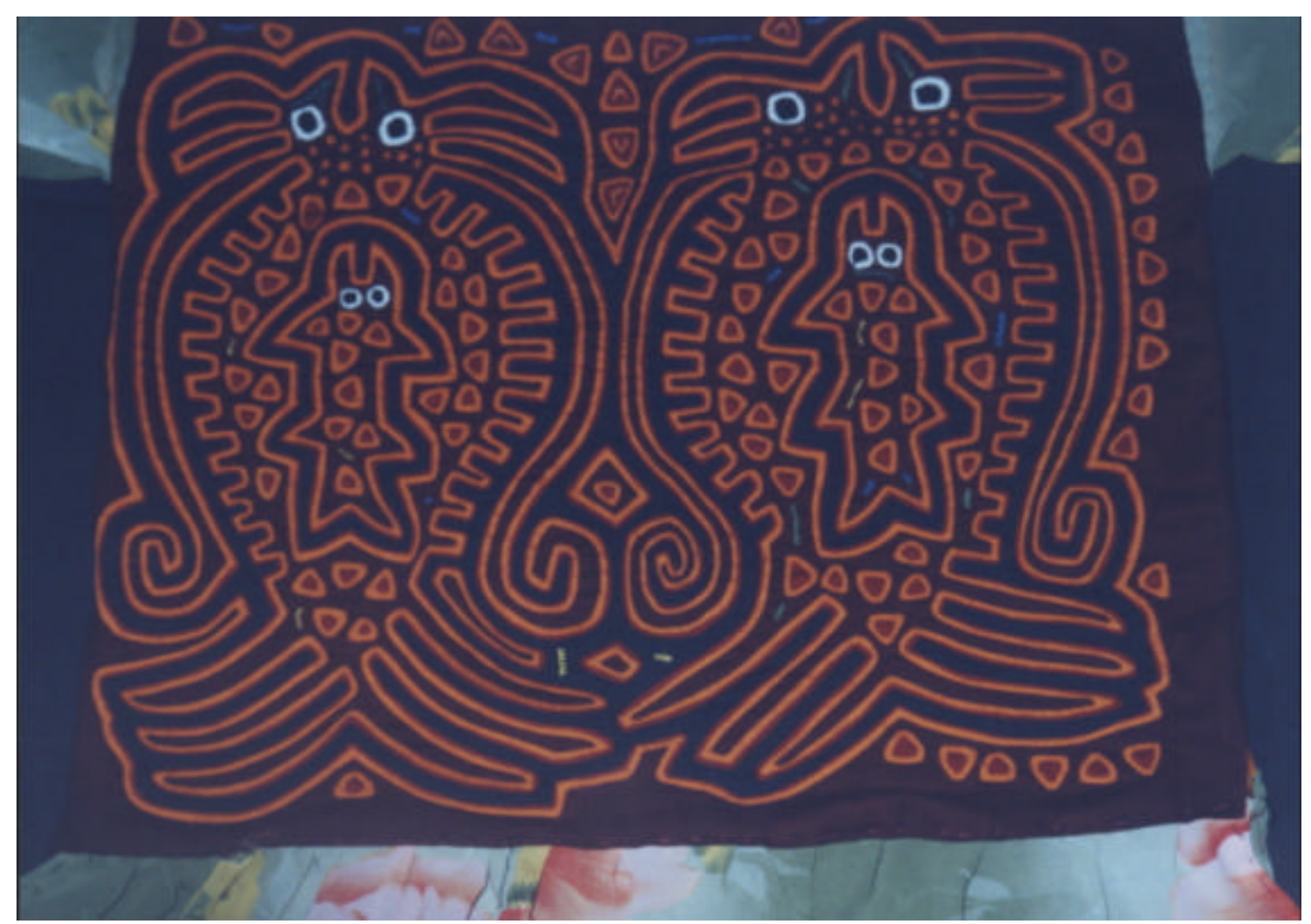

Sergan mola de dos pescados. Foto: MARTINEZ MAURI, 2003.

\section{Conclusión:}

Al trazar el vínculo entre lo material y lo simbólico, se hace evidente que ambos procesos nacen en la esfera social y a raíz de actividades humanas. La relación que establece una sociedad con sus ecosistemas tiene que ver con la dicotomía culturanaturaleza.

La relación material del pueblo kuna con el mar se concretiza en la pesca y en la extracción de recursos marinos para la construcción. Las actividades humanas perturban inevitablemente los ecosistemas marinos de Kuna Yala. Los residuos domésticos, las crecidas de los ríos y el calentamiento global del planeta parecen ser las causas de la progresiva disminución de la cobertura coralina de la región. Hoy en día algunas especies marinas con alto valor comercial, como por ejemplo las langostas (Panulirus argus), son víctimas de la sobreexplotación. Otras, como los corales, sufren los efectos provocados por los residuos. Aunque los pescadores son conscientes de estos cambios, 
pocos son los que han adoptado prácticas más respetuosas con el medio. Los kunas necesitan el coral muerto para aumentar la superficie de sus islas y construir muelles. Dado que la cría de animales es prácticamente inexistente y la caza es muy esporádica, no pueden dejar de pescar. Sin pescado la dieta kuna sería demasiado pobre en proteínas animales. Afortunadamente, en Kuna Yala la pesca continua siendo una actividad artesanal. Todavía no hay redes de arrastre ni medios técnicos adecuados para explotar a gran escala los recursos de las aguas profundas.

En el ámbito simbólico, el mar es un lugar fértil, poblado de recursos infinitos y dominado por criaturas peligrosas. Para los kunas es una entidad de naturaleza femenina, como la abuela (Muи) que trae los bebés al mundo. La apropiación simbólica de los recursos marinos se caracteriza por las prohibiciones que marcan la relación con algunos animales marinos. Los tabúes refuerzan la idea de que los alimentos modelan el cuerpo y el alma (purba). El consumo de animales innobles o impuros, tanto marinos como terrestres, puede tener consecuencias muy graves para algunas personas, ya que pueden adoptar las características y los vicios propios del animal.

Aunque los kunas sostengan que la relación que mantienen con el mar no es tan espiritual como la que tienen con la madre tierra, el mar tiene un alto contenido simbólico en la tradición kuna. Esto queda demostrado a partir del análisis de los miedos, los tabúes y los mitos. Si el pueblo kuna ha insistido tanto en la relación simbólica y espiritual con los bosques de Kuna Yala, es por las presiones de los nuevos valores ecológicos de la sociedad occidental (Cf. Martínez Mauri, 2003). La alianza entre los ecologistas y el movimiento indígena, ha convertido la conservación de los bosques tropicales en el caballo de batalla de la lucha internacional. La visibilidad obtenida por el movimiento indígena a raíz de la Conferencia de las Naciones Unidas sobre el Medio Ambiente y el Desarrollo (Rio de Janeiro, 1992) ha dirigido las acciones de las Organizaciones no gubernamentales (ONG) indígenas hacia la aplicación de programas para la conservación de la biodiversidad de los ecosistemas forestales, pero no de los marinos. Hoy en día, cuando se habla de áreas protegidas o del uso sostenible 
de los recursos naturales se piensa en el ecosistema forestal ${ }^{18}$, pero no en el marino. El estudio y la gestión de los recursos marinos sigue siendo un asunto pendiente en Kuna Yala y en el resto de América Latina.

\section{Bibliografía}

ABELLÓ, P. y D. DIAZ (2001) Informe de misión: Consideraciones para un manejo adecuado de la pesquería de langosta (panulirus argus) en la comarca de Kuna Yala (Panamá). Componente de manejo de la langosta del proyecto "manejo sostenible de los recursos marinos en kuna yala", mecanografiado, AECI / Institut de Ciències del Mar / CSIC, Barcelona.

ABELLÓ, P. y D. DIAZ (2003) Informe de misión: Educación ambiental en materia de recursos marino-costeros en la comarca indígena de Kuna Yala, AECI, Panamá, Institut de Ciències del Mar, Barcelona.

ACHESON, J.M. (1981) "Anthropology of fishing", Annual Reviews of Anthropology, 10: $275-316$.

BELLAN, G. y J. M. PÉRÈS (1994, $1^{\text {a }}$ edición 1974) La pollution des mers. "Que saisje?" Presses Universitaires de France, París.

BRENNAN HATLEY, N. (1976) "Cooperativism and Enculturation among the Cuna Indians of San Blas". Johames WILBERT (Ed.) Enculturation in Latin America. An anthology. UCLA, Latin American Center Publications. University of California. Los Angeles.

CHAPIN, M. (1989) Pab Igala. Historias de la Tradición Kuna. Quito-Equador: Ediciones Abya-Yala. (mecanografiado)

CHAPIN, M. (1983) Curing among the San Blas Kuna of Panamá, Ph. D., manuscrito, Universidad de Arizona.

CHARNLEY, S. y C. de LEÓN (1986) Uso de recursos silvestres en Kuna Yala. Mecanografiado, Panamá.

CLIFTON, K. E.; K. KIM y J. L. WULFF (1996) Guía de campo para los arrecifes del Caribe de Panamá con énfasis en el sector occidental de San Blas, $8^{\circ}$ Simposio Internacional sobre Arrecifes de coral, Panamá.

COLCHESTER, M. (1995) Salvando la naturaleza: Pueblos indígenas, Areas protegidas y conservación de la biodiversidad. Genève: UNRISD. 74 p.

CONGRESO GENERAL KUNA (2001) Anmar igar. Normas kunas. Panamá.

CORBIN, A. (2000, $1^{\mathrm{a}}$ edición 1988) Le territoire du vide. L'Occident et le désir du rivage (1750-1840). Flammarion, París.

CORDINGLY, D. (2003, $1^{a}$ edición en inglés 2000) Mujeres en el mar. Capitanas, corsarias, esposas y rameras. Tierra incógnita, Edhasa, Barcelona.

\footnotetext{
${ }^{18}$ Cf. Colchester (1995)
} 
DD:AA: FAO species identification sheets for fishery purposes Field guide to the commercial marine and brackish - water resources of the Northern coast of South America. FAO, CEC, NORAD, Roma, 1993.

DELUMEAU, J. (1978) La peur en Occident, XIV-XVIII siècles, Paris, Fayard.

DESCOLA, P. (1986) La nature domestique. Symbolisme et praxis dans l'écologie des Achuar. Editions de la Maison des Sciences de l'homme, Paris 450 p.

DESCOLA, P. (1996) "Constructing natures. Symbolic ecology and social practice", in: EASA: Nature and Society Anthropological Perspectives. Ed. P. Descola, Gisili Pálsson. Londres: EASA : 82-102.

FORICHON, J. (2003) Les Kuna du Panama confrontés à la gestion de nouveaux déchets ménagers. Recherche d'une problématique 'environnementdéveloppement' en milieu amérindien. Mémoire de recherche, manuscrito, Université d'Orleans.

GUZMÁN, H. M.; Carlos GUEVARA, Arcadio CASTILlO (2003) "Natural disturbances and mining of Panamanian Coral Reefs by Indigenous People", Conservation Biology, vol. 17, no. 5 : 1396-1401.

HASBROUCK, G.M. (1985) Subsistence fishing among the San Blas Kunas, Panamá, M.A. thesis, manuscrito, Universidad de California, Berkeley.

HOLlOMAN, R. (1969) Developmental change in San Blas, Ph. Disseration. Northwestern University. $524 \mathrm{p}$.

HOLLOMAN, R. (1975) "Ethnic boundary maintenance, readaptation and societal evolution in the San Blas islands of Panamá". Leo A. DESPRES, Ethnicity and resource comptetition in plural societies. Mouton publishers, The Hague - París.

HOWE, J. (1974) Village political organization among the San Blas Cuna, Dissertation in Anthropology, manuscrito, Universidad de Pennsylvania.

HOWE, J. (1986). The Kuna Gathering: Contemporary Village Politics in Panama. Austin: University of Texas Press. 326 p.

HOWE, J. (1998) A people who would not kneel. Panama, the United States, and the San Blas Kuna. Washington: Smithsonian Institution. 390 p.

HUMANN, P. (1996, $1^{\text {a }}$ edición 1992) Reef creature identification. Florida, Caribbean, Bahamas. Edited by Ned Deloach, New World Publications Inc. Jacksonville, Florida. 320 pp.

HUMANN, P. y D., Ned (2002, $1^{\text {a }}$ edición 1989) Reef fish identification. Florida, Caribbean, Bahamas. New World Publications, Inc. Jacksonville, Florida.

LASKER, H.R., E.C. PETERS, y M .A. Coffroth (1984) Bleaching of reef coelenterates in the San Blas Islands, Panamá. Coral Reefs, 3: 183-190.

LATOUR, B. (1988) Le Grand Partage. In: La revue du MAUSS. Mouvement Antiutilitariste en Sciences Sociales. № 1. Paris: La Découverte. : 27-64

LATOUR, B. (1997 [1991]) Nous n'avons jamais été modernes. Essai d'anthropologie symétrique. Paris: La Découverte/Poche. 208 p.

LEAP, W. L. (1977) "Maritime subsistence in anthropological perspective: a statement of priorities. M.E. SMITH (ed.) Those who live from the sea, St. Paul, West Publishing Company : 251-263.

LÉVI-STRAUSS, C. (1974) Anthropologie structurale. Plon, París. 
MARTÍNEZ MAURI, M. (2003) Médiation et développement. L'émergence des ONG et des passeurs culturels à Kuna Yala (Panamá). Collection Itinéraires $\mathrm{N}^{\circ} 16$. Publications de l'IUED. Ginebra.

NORDENSKIÖLD, E. (1928) "An Historical and Ethnological Survey of the cuna indians". Comparative Ethnographical Studies, n 10. Göteborg.

NORDENSKIÖLD, E. (1929) "Les rapports entre l'art, la religion et la magie chez les indiens cuna et chocó". In: Journal de la Societé des americanistes de Paris, $\mathrm{n}^{\circ}$ 21, Paris: 141-158

PÁLSSON, G. (1991) Coastal economies, cultural accounts. Human ecology and Icelandic discourse. Manchester University Press, Manchester.

PERRIN, M. (1998) Tableaux kuna. Les molas, un art d'Amérique, Arthaud, París.

PRESTÁN SIMON, A. (1975) El uso de la chicha en la sociedad kuna. Ediciones especiales, 72, Instituto Indigenista Interamericano, México.

PUIG, M. M. (1946) Los indios cunas de San Blas. Su origen, tradiciones, costumbres, organización social, cultura y religión, Panamá. 229 p.

SANDNER, V. (1998) Uso de recursos marinos en Kuna Yala, Panamá: problemas actuales y percepción de la población indígena. Kiel, Alemania. Mecanografiado.

SCHULMAN, M. J., y D.R. ROBERTSON (1996) changes in the coral reefs of San Blas, Caribbean Panamá: 1983-1990. Coral Reefs 15: 231-236.

SHATTO, G. (1969) "The San Blas Indian Sociedad as a vehicle of economic development". Paper, $3^{\text {rd }}$. University of Houston Annual Conference on Latin America.

SHERZER, J. (1990) Verbal Art in San Blas. Kuna culture through its discourse. Cambridge University Press. 281 p.

SHERZER, J. (1983). Kuna Ways of Speaking. Austin: University of Texas Press.

SPADAFORA, A. (2000) Pesquería de la Langosta Panulirus argus en el Archipiélago de San Blas, Kuna Yala, Panamá: Antecedentes históricos y diagnóstico general. Programa de Apoyo al Desarrollo de la Pesca en el Istmo Centroamericano / Unión Europea.

STIER, F. R. (1979) The effect of demographic change on agriculture in San Blas, Panama. Ph. D. manuscrito, Universidad de Arizona.

STOUT, D. (1947). San Blas Cuna Acculturation: An Introduction. Viking Fund. New York. 124 p.

TICE, K. E. (1995). Kuna Crafts, Gender, and the Global Economy. University of Texas Press. Austin. 232 p.

VENTOCILLA, J; HERRERA, H.; NUNEZ, V. (1995) Plants and Animals in the life of the kuna People, Hans Roeder, editor. University of Texas Press. Austin. 150 p.

WAGUA, A. (2000) En defensa de la vida y su armonía. Congreso General de la Cultura Kuna / Instituto de investigaciones Koskun Kalu. Panamá. 


\section{Resumen:}

Desde hace siglos, el pueblo kuna o tule explota los recursos de la costa atlántica de Panamá. En la dieta kuna, el pescado constituye el $80 \%$ de las proteínas animales. Todavía persisten tabúes sobre el consumo de algunas especies marinas y muchos animales acuáticos pueden atacar el espíritu (purba) de los kunas. Pese a que la literatura etnográfica sobre la región es extensa, pocos trabajos han abordado las representaciones de la naturaleza. Con el objetivo de llenar este vacío, me propongo presentar las actividades de pesca, el uso de los recursos marinos y la representación del mar en Kuna Yala. En este trabajo hago referencia a las técnicas, los lugares y la división social del trabajo relacionados con la pesca. También considero la responsabilidad de los kunas en la transformación y contaminación de los ecosistemas marinos de la región. Finalmente, a partir del análisis de los mitos, la representación de los recursos marinos en el arte, los tabúes alimentarios y las concepciones emic de la gestación y el parto, describo la relación simbólica que establece el pueblo kuna con el mar.

\section{Abstract:}

During centuries, the kuna (or tule) people have exploited the natural resources of the Atlantic Coast of Panama. Fish represents $80 \%$ of animal proteins in the kuna diet. Taboos concerning the consumption of marine species are still alive and many aquatic animals can attack the spirit (purba) of the kuna. The ethnographic literature about the region didn't focus on the kuna representation of nature. My propose is to study techniques, places and social division of labor related with fishing. I will also attempt to identify anthropogenic disturbances in coral reef transformation and degradation. Finally, the myths, the representations of natural resources in the art, the taboos and the emic conception of pregnancy and birth will show the kuna symbolic relationship to sea. 


\section{Resumée:}

Depuis des siècles, le peuple Kuna ou Tule exploite les ressources naturelles de la côte atlantique du Panama. Le poisson représente le $80 \%$ du régime alimentaire kuna. Il existe encore des tabous sur la consommation de quelques espèces marines et nombreux animaux aquatiques peuvent attaquer l'âme (purba) des Kunas. Même si la littérature ethnographique sur la région est vaste, peu de travaux ont été consacrés aux représentations de la nature. Avec le but de combler ce vide, je me propose de présenter ici les activités de pêche, l'usage des ressources maritimes et la représentation de la mer chez les Kunas. Dans cette étude je fais référence aux techniques, aux endroits et à la division sexuelle du travail par rapport a la pêche. Je considère également la responsabilité des Kunas dans la transformation et contamination des écosystèmes marins de la région. Enfin, a partir de l'analyse des mythes, de la représentation des ressources maritimes dans l'art, des tabous alimentaires et des conceptions emic sur la grossesse et l'accouchement, je présente la relation symbolique que le peuple kuna entretien avec la mer. 